

\title{
FRICTION AND WEAR PROPERTIES OF SMOOTH DIAMOND FILMS GROWN IN FULLERENE-ARGON PLASMAS
}

\author{
A. Erdemir, G. R. Fenske, C. Bindal, C. Zuiker, A. R. Krauss, and D. M. Gruen \\ Materials Science, Chemistry, and Energy Technology Divisions \\ Argonne National Laboratory, Argonne, IL 60439, USA
}

\section{ABSTRACT}

In this study, we describe the growth mechanism and the ultralow friction and wear properties of smooth (20-50 nm rms) diamond films grown in a microwave plasma consisting of $\mathrm{Ar}$ and fullerene (the carbon source). The sliding friction coefficients of these films against $\mathrm{Si}_{3} \mathrm{~N}_{4}$ balls are 0.04 and 0.1 in dry $\mathrm{N}_{2}$ and air, which are comparable to that of natural diamond sliding against the same pin material, but is lower by factors of 5 to 10 than that afforded by rough diamond films grown in conventional $\mathrm{H}_{2}-\mathrm{CH}_{4}$ plasmas. Furthermore, the smooth diamond films produced in this work afforded wear rates to $\mathrm{Si}_{3} \mathrm{~N}_{4}$ balls that were two to three orders of magnitude lower than those of $\mathrm{H}_{2}-\mathrm{CH}_{4}$ grown films. Mechanistically, the ultralow friction and wear properties of the fullerene-derived diamond films correlate well with their initially smooth surface finish and their ability to polish even further during sliding. The wear tracks reach an ultrasmooth (3-6 nm rms) surface finish that results in very little abrasion and ploughing. The nanocrystalline microstructure and exceptionally pure $\mathrm{sp}^{3}$ bonding in these smooth diamond films were verified by numerous surface and structure analytical methods, including $X$-ray diffraction, high-resolution AES, EELS, NEXAFS, SEM, and TEM. An AFM instrument was used to characterize the topography of the films and rubbing surfaces.

KEY WORDS: Smooth diamond films, nanocrystalline microstructure, Ar-fullerene plasma, ultralow friction and wear. 


\section{INTRODUCTION}

Attractive mechanical and tribological properties of policrystalline diamond (PCD) and amorphous carbon films make them good prospect for a wide range of engineering applications including bearings, seals, and cutting tools [1-6]. In applications where high contact stresses and thermal cycling are experienced (such as in tribology), it is important that these films have strong adhesion, very smooth surface finish, and high thermal stability [7-9].

In recent years, considerable progress has been made in the deposition and commerical utilization of amorphous carbon films (both hydrogenated and hydrogen free) [5,6-10], but their uses are limited by graphitization at elevated temperatures $[9,11,12]$. In so far as the PCD films are concerned, the progress has been rather slow. Currently, the technology is limited by such barriers as poor adhesion, slow growth rates, and rough surface finish. In particular, it has been difficult to produce smooth diamond films without a compromise between film quality and deposition rate. In most cases, the films consisted of large diamond grains with nondiamond material between them.

The generally rough surface finish of PCD films precludes their immediate use for most machining and wear applications. When used in sliding-wear applications, such rough films cause high friction and very high wear losses on the mating surfaces [13-15]. In machining operations, these films result in a rough surface finish on final products [13]. In recent years, attempts have been made to develop effective chemical etching and mechanical polishing techniques. However, the extreme hardness of diamond made mechanical polishing very difficult, and the chemical inertness of 
diamond made most chemical etching and lithographic processing techniques ineffective. Techniques using laser beams appear to be more successful but require longer processing time [16]. These additional steps increase the cost of the final products and are difficult or impossible to apply to complex shapes. In short, the general consensus is that efficient ways must be found to produce smooth diamond films and to increase their deposition rates before diamond coatings become sufficiently cost-effective to warrant their widespread utilization in machining and sliding wear applications.

In this paper, we describe a new process that can grow smooth diamond films $(20-50 \mathrm{~nm} \mathrm{rms})$ that impart very low friction and wear to sliding ceramic counterfaces. The process is based on a microwave plasma consisting essentially of Ar and fullerene (the carbon source). The ultralow friction and wear properties of these films correlate well with their initially smooth surface finish and their ability to polish even further during sliding to reach an ultrasmooth (3-6 nm rms) surface finish that results in very little abrasion and ploughing.

\section{EXPERIMENTAL DETALS}

\section{Test Material}

The flat substrates used in this study were made of silicon wafers and sintered $\mathrm{SiC}$ materials. The counterface balls were made of $\mathrm{SiC}$ pins and $\mathrm{Si}_{3} \mathrm{~N}_{4}$ balls $(9.5 \mathrm{~mm}$ in diameter). Their surface finish was better than $0.01 \mu \mathrm{m}$ center-line-average (CLA). Prior to testing, all balls were ultrasonically cleaned sequentially in hexane +10 vol.\% toluene, acetone, deionized water containing $2 \mathrm{wt} . \%$ 
laboratory detergent, and deionized water for about $1 \mathrm{~min}$ each, then dried in an oven at $100^{\circ} \mathrm{C}$ for $10 \mathrm{~min}$.

\section{Film Deposition}

Diamond films were deposited in a microwave plasma chemical vapor deposition reactor (ASTeX PDS-17) as previously described $[17,18]$. The films were grown on single crystal silicon wafers or sintered $\mathrm{SiC}$ and a bias of $-150 \mathrm{~V}$ was applied to enhance diamond nucleation density. Film growth was monitored in situ using laser reflectance interferometry to determine growth rate and stop growth at the desired film thickness. All films were grown with the substrate temperature between 800 and $850^{\circ} \mathrm{C}$ and the total gas flow rate of $100 \mathrm{sccm}$. For smooth films, the gas composition consisted of $98 \% \mathrm{Ar}, 2 \% \mathrm{H}_{2}$ and $\mathrm{C}_{60}$, at 100 Torr pressure and $800 \mathrm{~W}$ of microwave power. Rough, faceted films were grown using typical growth conditions of $98 \% \mathrm{H}_{2}, 2 \% \mathrm{CH}_{4}$, at 60 Torr pressure and $1500 \mathrm{~W}$ of microwave power.

\section{Film Characterization}

The films were characterized by a variety of techniques, including Raman spectroscopy, $x$-ray diffraction measurements (XRD), Auger electron spectroscopy (AES), transmission electron microscopy (TEM), atomic force microscopy (AFM), and scanning electron microscopy (SEM). Raman spectra of the films were measured with a Renishaw Raman microscope using a HeNe laser at $632.8 \mathrm{~nm}$ with an output power of $25 \mathrm{~mW}$ focused to a spot size of about $2 \mu \mathrm{m}$. Raman spectroscopy is widely used to characterize diamond films, although the small grain size in the 
smooth, $\mathrm{C}_{60}$ grown films has a significant effect on the Raman spectrum. A Phillips powder diffractometer with $\mathrm{Cu} K_{\mathrm{a}}$ was used for XRD measurements to ensure the presence of diamond and check for evidence of crystalline graphite. AES spectra were obtained using a physical electronics model 548 with double pass cylindrical mirror analyzer. The carbon KLL peak is sensitive to the bonding state of carbon, providing a qualitative means of assessing the $\mathrm{sp} 2 / \mathrm{sp}^{3}$ ratio of the films. TEM imaging was performed in the JEOL 4000EXII operating at $400 \mathrm{kV}$. Specimens for TEM were prepared using standard dimpling and ion milling procedures. The surface was characterized using a Burleigh ARIS-3300 AFM to measure the root mean square (rms) surface roughness and a JEOL JXA-840A SEM to image the surface.

\section{Friction and Wear Tests}

We conducted friction and wear tests on a ball-on-disk tribometer with pairs of $\mathrm{SiC}$ pins or $\mathrm{Si}_{3} \mathrm{~N}_{4}$ balls and diamond-coated substrates in dry $\mathrm{N}_{2}$ and open air of 30 to $50 \%$ relative humidity. The normal load applied to the balls was 2 to $5 \mathrm{~N}$, which initially created mean Hertzian contact pressures of approximately 0.6 to $0.8 \mathrm{GPa}$ (ignoring any effects of the diamond films) between $\mathrm{Si}_{3} \mathrm{~N}_{4}$ and $\mathrm{SiC}$. Because of the formation of a flat wear scar during sliding contact, nominal bearing pressures fell to a fraction of these initial Hertzian values by the end of the tests. Frictional force was monitored with the aid of a load cell and was recorded on chart paper throughout the tests. The sliding velocity ranged from $0.050 .2 \mathrm{~m} / \mathrm{s}$ during tests. A few tests were run to assess the long-term tribological performance and durability of diamond coatings under a 5-N load at 0.04 $\mathrm{m} / \mathrm{s}$. Wear-volume calculations on the balls were based on microscopic determination of the diameter of the circular wear scars, combined with the assumption that the wear scar is flat. These 
wear volumes were converted into average specific wear rates by simply normalizing wear volume $\left(\mathrm{mm}^{3}\right)$ over contact load $(\mathrm{N})$ and total sliding distance $(\mathrm{m})$. The wear of disk specimens was assessed from the traces of surface profiles across the wear tracks. Two to three duplicate tests were run under each test condition to check the reproducibility of the friction and wear data, and the average values with the spread are reported.

\section{RESULTS:}

\section{Film Microstructure and Chemistry}

Figure 1 is a cross-sectional SEM photomicrograph of the diamond film used in this study. At the magnification shown, this film appears dense and smooth. The rough surface finish and coarse columnar morphology, typical of most $\mathrm{CH}_{4} / \mathrm{H}_{2}$ grown PCD films with larger grain sizes, is not obvious in this film. It has been characterized as nanocrystalline diamond film. As shown in Figure 2 , the characteristic (111), (220) and (311) diamond peaks are evident in the XRD pattern and there is no evidence of the strong (002) graphite peak at $26.4^{\circ}$. This indicates that the films contain diamond and no appreciable amounts of other crystalline phases.

Evidence of low sp $2 / \mathrm{sp}^{3}$ carbon ratios in the films is obtained from AES measurements of the carbon KLL peak, which is sensitive to the bonding state of the carbon atom and has been used to determine $\mathrm{sp}^{2} / \mathrm{sp}^{3}$ ratios in a-C:H films [19]. The AES spectra are very similar to those reported in the literature for diamond [20-22], indicating a low sp $/ \mathrm{sp}^{3}$ ratio. Further evidence of low 
$\mathrm{sp}^{2} / \mathrm{sp}^{3}$ ratios in these films have recently been obtained using Photoabsorption Near-Edge X-ray Absorption Fine Struture NEXAFS measurements, which clearly distinguish between $\mathrm{sp}^{2}$ and $\mathrm{sp}^{3}$ carbon bonding. These measurements show the films are indeed diamond and contain little $\mathrm{sp}^{2}$ bonding [23].

High resolution transmission electron microscopy (HRTEM) has been used to examine the microstructure of films grown with fullerene precursors and indicates the films are composed of small diamond grains $(10 \mathrm{~nm}-300 \mathrm{~nm})$ [24]. For smooth $\mathrm{C}_{60}$ grown films, the average grain size was determined to be $15 \mathrm{~nm}$.

The Raman spectra of the films show a peak at $1332 \mathrm{~cm}^{-1}$ attributed to diamond. Additional broad features at 1580 and $1330 \mathrm{~cm}^{-1}$ have been attributed to $\mathrm{sp}^{2}$ carbon [25]. An additional feature around $1140 \mathrm{~cm}^{-1}$ appears for $\mathrm{C}_{60} / \mathrm{Ar} / \mathrm{H}_{2}$ grown films which has been attributed to nanocrystalline diamond $[26,27]$. The $1332 \mathrm{~cm}^{-1}$ peak for the $\mathrm{C}_{60} / \mathrm{Ar} / \mathrm{H}_{2}$ grown films is weak relative to other Raman features. This is attributed to the small grain size in the films rather than an increase in the $\mathrm{sp}^{2} / \mathrm{sp}^{3}$ carbon ratio. The $1332 \mathrm{~cm}^{-1}$ peak intensity has been shown to decrease with decreasing grain size for diamond films [28,29]. Furthermore, these Raman spectra were excited using $632.8 \mathrm{~nm}$ light, which is more sensitive to the nondiamond carbon phases than the $488 \mathrm{~nm}$ Argon ion laser light commonly employed for measuring Raman spectra [30]. The present interpretation is supported by the TEM images, which indicate that the film is nanocrystalline, as well as the AES and XRD data, which indicate the $\mathrm{sp}^{2} / \mathrm{sp}^{3}$ ratios of the films are similar to diamond and the only crystalline component in the films are diamond. 
From AFM measurements of rms surface roughness, the $\mathrm{CH}_{4} / \mathrm{H}_{2}$ grown films were found to grow rougher with increasing thickness. The $\mathrm{C}_{60} / \mathrm{Ar} / \mathrm{H}_{2}$ grown films were found to remain smooth as film growth proceeded, with rms roughnesses in the range of $30-50 \mathrm{~nm}$.

\section{Friction and Wear}

Figure 3 compares the friction coefficients of SiC pins sliding against the smooth and rough diamond films in dry $\mathrm{N}_{2}$. The SEM micrographs in Figure 4 show the surface finish of these films. The friction coefficient of rough diamond film is high and very unsteady. It fluctuates between 0.45 and 0.7 . Whereas, the friction coefficient of smooth diamond film is around 0.04 at steady state. SEM micrograph of the wear track formed on smooth diamond film revealed a highlypolished, ultra-smooth surface finish (see Fig. 5a), whereas the wear track of rough diamond film was covered with a layer of thick debris particles as shown in Fig. 5b. The wear of SiC pin sliding against the rough diamond film was $6.5 \times 10^{-6} \mathrm{~mm}^{3} / \mathrm{N}$.m. Whereas the wear rate of pin slid against the smooth diamond film was $2.5 \times 10^{-7} \mathrm{~mm}^{3} / \mathrm{N} . \mathrm{m}$. As for the wear of diamond films, it was practically unmeasureable in both cases.

Figure 6 shows the friction coefficients of $\mathrm{Si}_{3} \mathrm{~N}_{4}$ balls against smooth diamond film in dry $\mathrm{N}_{2}$ and in open air. For comparison, the friction coefficient of a highly-oriented-pyrolitic-graphite (HOPG) sample is also included. Regardless of the environment, the initial friction coefficient of diamond film against $\mathrm{Si}_{3} \mathrm{~N}_{4}$ is high, i.e., 0.35 , but decreases steadily as sliding continues. In dry $\mathrm{N}_{2}$, the friction coefficient stabilizes at around 0.04 after about 1,500 cycles and remains fairly constant at this value until reaching 10,000 cycles. It then begins to increase with further sliding eventually 
reaching a value of 0.31 after 15,000 cycles. As can be seen from the same graph, the average friction coefficient of HOPG against $\mathrm{Si}_{3} \mathrm{~N}_{4}$ is around 0.25 and the friction trace is highly erratic. As for the smooth diamond film tested in air, its friciton coefficient is initially high, i.e., 0.35 , but decreases to 0.13 and remains constant throughout the test.

Figure 7 presents the variation of friction coefficient of $\mathrm{Si}_{3} \mathrm{~N}_{4}$ balls sliding against the smooth diamond film during a long-duration test. It lasted 2.27 million cycyles (or $36 \mathrm{~km}$ ). As is evident, the initially high friction coefficient, i.e., 0.35 decreases to 0.12 with increasing number of sliding cycles. The friction coefficient tends to increase slightly to 0.15 after 75,000 sliding cycles and remains constant at this value. The average specific wear rate of the counter face ball was $1.4 \mathrm{X}$ $10^{-8} \mathrm{~mm}^{3} / \mathrm{N}$.m. Figure 8 shows a 3-D surface map of the wear track formed on this diamond film after accumulating 2.25 million sliding passes. The depth of this track was measured with a surface profilometer to be $0.5 \mu \mathrm{m}$. The film itself was $6 \mu \mathrm{m}$ thick.

\section{DISCUSSION:}

The result presented above clearly demonstrate that the smooth diamond films produced in this study can impart very low friction coefficients and low wear rates to sliding $\mathrm{SiC}$ and $\mathrm{Si}_{3} \mathrm{~N}_{4}$ surfaces in dry $\mathrm{N}_{2}$ and open air. The amount of wear in these diamond films is very negligible and unmeasurable after shorther duration tests. It took 2.27 million sliding cycles under a load of 5 $\mathrm{N}$ to generate a $0.5 \mu \mathrm{m}$ deep wear track on this film (Fig. 8). The exceptional wear resistance of smooth diamond films used in this study is primarily attributed to their high mechanical strength and hardness. 
The results presented in Figs. 3 and 6 manifest the ultralow friction character of the fullerenederived smooth diamond films. The low friction values shown in these figures correlate well with the initially smooth surface finishes (i.e., $30 \mathrm{~nm}, \mathrm{rms}$ ) of these films, and their ability to polish even further during sliding to reach an ultrasmooth $(3 \mathrm{~nm} \mathrm{rms}$ ) surface finish (see Fig. 5 a) that results in very little abrasion and ploughing. These friction coefficients are comparable to that of natural diamond sliding against $\mathrm{Si}_{3} \mathrm{~N}_{4}$ in dry $\mathrm{N}_{2}$ and air as reported earlier in Ref. 31 .

Physically, rougher surfaces can cause increased ploughing, and hence higher friction. The high friction coefficient of the rough diamond film can be attributed to the abrasive cutting and ploughing effects that sharp surface asperities (Fig. 4b) have on softer SiC pin. The similar argument can be used to explain the initially high, i.e., 0.35 friction coefficient of smooth diamond film as well. Apparently, during repeated sliding passes, surface asperities of this film are broken-in or flattened-out after a run-in period, hence the magnitude of microcutting and ploughing contributing to higher friction is reduced. Previous investigation has confirmed that surface topography of diamond films relates closely to their friction and wear performance. In general, the higher the surface roughness the larger the friction and wear losses $[7,14,15]$. Our findings are consistent with these initial reports.

For the very low friction character of smooth diamond films in open air and the ultra-low friction values in dry $\mathrm{N}_{2}$, we propose the following interpretation. As reported by a number of researchers [32-37], active species like hydrogen, oxygen, or water vapor can attach and passivate the dangling surface bonds of most carbon materials, including diamond and graphite. Apparently, when the dangling bonds are passivated, the adhesion component of friction is drastically reduced 
in sliding contacts. In fact, the low-friction character of diamond is solely attributed to the highly passive nature of its sliding surface [3+-36]. When hydrogen and other species are desorbed or removed from the sliding surfaces, the friction coefficient of diamond increases drastically, presumably because the reactivated dangling bonds cause strong adhesive interactions between the diamond and the counter face materials [32,34-37]. Recent studies by Gardos et al. $[8,36,38,39]$ have demonstrated very clearly that the friction coefficients of diamond films sliding. against $\mathrm{Si}, \mathrm{SiC}$, or diamond-coated $\mathrm{SiC}$ couterfaces could increase substantially if surface adsorbates were removed from the surface by means of annealing in high vacuum. Conversely, if atmospheric air is admitted into the test chamber, the friciton coefficient drops precipitously. Thus, the low friction character of smooth diamond films used in this study can also be attributed to the presence of surface adsorbates passivating the dangling bonds of diamond films essentially making them very inert and chemically insensitive to counterface materials.

It is interesting to note that the friction coefficient of diamond film remains constant in air but increases substantially in dry $\mathrm{N}_{2}$ as sliding continues beyond 10,000 cycles. For this disparity, we propose the following interpretations. During dynamic rubbing, the adsorbate layer is either desorbed by frictional heating or removed mechanically by microfracture or wear thus exposing the fresh and active dangling bonds of diamond surface. Without continious replenishment, these bonds can become more and more active and start exerting some adhesive forces across the sliding interface, thus causing increasingly higher friction. Alternatively, a combination of high frictional heating and very high contact stresses at colliding asperity tips can over the course of several thousand sliding passes cause gradual graphitization of these sharp tips. As the graphitization becomes wide spread and constitutes a third-body interlayer between sliding surfaces, then the 
frictional behavior of $\mathrm{Si}_{3} \mathrm{~N}_{4} /$ diamond interface can partially be dominated by the shear properties of this entrained graphitic material.

We could not design a test where we could do a very careful in-situ surface analysis to verify if the first hypothesis was valid (note that there are already some very good papers dealing with this subject in open literature [32-39]), but we performed the following simple experiment in a naive manner to test the second hypothesis. Specifically, after accumulating over 160,000 to 180,000 sliding cycles on the same samples used in Fig. 3 , we turned of the dry $\mathrm{N}_{2}$ valve and gradually bled ambient air into the test chamber while the sliding test was still continuing. As shown in Fig. 9, the friction coefficients of both diamond and HOPG against $\mathrm{Si}_{3} \mathrm{~N}_{4}$ dropped precipitously to 0.1 . The sharp decrease in the friction coefficient of HOPG is not surprising, because this material is known to lubricate the best in moist environments. However, it is very interesting to note that the friction coefficient of diamond film also drops instantly as soon as some air is introduced into the test chamber. Also, the large fluctuations in friction traces of both diamond film and HOPG disappear as air enters the chamber. The friction coefficient of diamond film in open air remains essentially constant and is comperable to those of the HOPG and the smooth diamond film tested in ope air.

In an attempt to see if there was any evidence of graphitization of the sliding diamond surfaces, we used a laser Raman spectroscope equipped with a HeNe laser operating at $632.8 \mathrm{~nm}$ with an output power of $25 \mathrm{~mW}$ and a spot size of $2 \mu \mathrm{m}$. We could not verify the formation of a detectable graphitic precursor on the sliding surface of diamond films after tests in open air, but there was some evidence of graphitization on surfaces rubbed in dry $\mathrm{N}_{2}$. As shown in Fig. 10, Raman spectroscopy of the debris particles formed during sliding in dry $\mathrm{N}_{2}$ reveals two broad 
Raman bands, one centered at 1345 and the other at $1578 \mathrm{~cm}^{-1}$. These two lines essentially overlap with the $D$ and $G$ bands of crystalline graphite. Raman spectroscopy of the debris particles produced in open air did not yield any indication of graphitization. The Raman spectrum of these debris particles was similar to that of the wear scar formed on $\mathrm{Si}_{3} \mathrm{~N}_{4}$ pin.

Based on this observation and more recent work by Gardos and Ravi [38,39], it is reasonable to conclude that surface graphitization plays a significant role on the longer-term frictional behavior of diamond films, especially in vacuum and dry $\mathrm{N}_{2}$. It is also important to note that in most tribological investigations, the sliding contact tests are usually limited to less than 20,000 sliding cycles, and the values obtained from such short-duration tests are used as the real indicator of the frictional behavior of diamond films. However, as the results of this study suggest, very long duration tests should also be run to ascertain the true frictional behavior of diamond films. Tribochemical and/or physical changes occurring during sliding contact are time dependent and steep transitions in friction and wear behavior are possible during long duration tests. This is very important because in most practical applications, these films will have to accumulate several millions of sliding passes.

It is important to remind that the hypotheses proposed here are based on observations made on the fullerene-drived diamond films developed and tested in this study. The family of diamond films is rather large, and depending on deposition method and/or condition, non-diamond phases and large amounts of hydrogen may be present in their structures. The films used here were essentially hydrogen-free, because they were deposited in an $\mathrm{Ar}-\mathrm{C}$ plasma. Therefore, the proposed friction mechanisms should not be regarded as universal and applicable to all diamond films produced by 
others.

\section{CONCLUSIONS}

1. Depostion of high-quality nanocrystalline diamond films with very smooth surface finish is feasible in a $\mathrm{Ar}-\mathrm{C}$ microwave plasma.

2. These nanocrystalline films are essentially hydrogen free and consist of $\mathrm{sp}^{3}$-bonded diamond precursor.

3. Because of their smooth surface finish, these films afford very low friciton and high-wear resistance to sliding $\mathrm{SiC}$ and $\mathrm{Si}_{3} \mathrm{~N}_{4}$ counterfaces. The wear of diamond film itself is hard to measure after short-duration tests, but very minimal even after 2.27 million sliding cycles.

4. Mechanistically, their low friction and wear properties correlate well with their initially smooth surface finish and their ability to polish even further during sliding. The wear tracks reach an ultrasmooth $(3 \mathrm{rms})$ surface finish that results in very little abrasion and ploughing.

5. The long-term frictional behavior of these films in dry $\mathrm{N}_{2}$ is dominated by micrographitization as verified by Raman. In open air, the evidence of graphitization has not yet been found. 


\section{ACKNOWLEDGMENTS}

This work was supported by the U.S. Department of Energy under Contract W-31-109-Eng-38. 


\section{REFERENCES}

1. 1. H. Tsai and D. B. Bogy, J. Vac. Sci. Technol., A5 (1987)3287-3312.

2. K. E. Spear, J. Am. Ceram. Soc., 72(1989)171.

3. "Status and Applications of Diamond and Diamond-like Materials: An Emerging Technology," National Materials Advisory Board, Washington D.C., (1990)

4. W. Banholzer and C. L. Spiro, Diamond Films and Technol., 1, 1991, pp. 115-126.

5. K. V. Ravi, Technological Applications of CVD Diamond, in Synthetic Diamond, (K. E.

Spear and J. P. Dismukes, eds.) The Electrochemical Society Series, John Wiley \& Sons, Inc., New York, p. 533, 1994.

6. J. F. Braza and T. S. Sudarshan, "Tribological Behavior of Diamond and Diamondlike Carbon Films: Status and Prospects," in Surface Modification Technologies V (T. S.

Sudarshan and J. F. Braza, eds.), The Institute of Materials, (1992), pp. 801-819.

7. M. Kohzaki, K. Higuchi, S. Noda, and K. Uchida, J. Mater. Res. 7(1992)1769.

8. M. N. Gardos, Tribology and Wear Behavior of Diamond, in Synthetic Diamond, (K. E. Spear and J. P. Dismukes, eds.) The Electrochemical Society Series, John Wiley \& Sons, Inc., New York, p. 419, 1994.

9. 16. K. Miyoshi, R. L. C. Wu, A. Garscadden, Surf. Coat. Technol., 54/55(1992) 428-434

10. A. Matthews and S. S. Eskildsen, Diamond and Related Mat., 3(1994)902.

11. A. Grill, Wear, 168(1993)143.

12. A. Erdemir, C. Bindal, G. R. Fenske, and P. Wilbur, Tribol. Trans., (1995) in press.

13. D. G. Bhat, D. G. Johnson, A. P. Malshe, H. Naseem, W. D. Brown, L. W. Schaper, and 
C. -H. Shen, Diamond and Related Mat., 4(1995)921.

14. I. P. Hayward, Wear, 157 (1992) 215-227

15. A.'K. Gangopadhyay and M. A. Tamor, Wear (1993)221.

16. U. Bogli, A. Blatter, S. M. Pimenov, E. D. Obraztsova, A. A. Smolin, M. Maillat, A.

Leijala, J. Burger, H. E. Hinterman, E. N. Loubnin, Diamond and Related Mat., 4(1995)1009.

17. D.M. Gruen, S. Liu, A.R. Krauss, and X. Pan, J. Appl. Phys. 75, 1758 (1994).

18. D.M. Gruen, S. Liu, A.R. Krauss, J. Luo, and X. Pan, Appl. Phys. Lett. 64, 1502 (1994).

19. A. Fuchs, J. Scherer, K. Jung and H. Ehrhardt, Thin Solid FIlms, 232, 51 (1993).

20. S. Craig, G.L. Harding and R. Payling, Surf. Sci. 124, 591 (1983).

21. S. Kasi, H. Kang, J.W. Rabalais, Phys. Rev. Lett. 59, 75 (1987).

22. A. Badzian and T. Badzian, Appl. Phys. Lett. 62, 3432 (1993).

23. J.A. Carlisle, D.G.S Sutherland, I. Jimenez, W. Tong, and L.J. Terminello (Personal Communication).

24. J.S. Luo, D.M. Gruen, A.R. Krauss, X.Z. Pan, and S.Z. Liu, Submitted for the proceedings of the Symposium on "The Fullerenes: Chemistry, Physics and New Directions", 187th Meeting of the Electrochemical Society, Reno Nevada, May 21-26, 1995.

25. D.S. Knight and W.B.White, J. Mater. Res. 4, 385 (1989).

26. R.J. Nemanich, J.T. Glass, G. Lucovsky, and R.E. Shroder, J. Vac. Sci. Technol. A 6, 1783 (1988).

27. W.A. Yarbrough and R. Roy, Proc. Mat. Res. Soc. EA-15, 33 (1988).

28. Y. Namba, E. Heidarpour and M. Nakayama, J. Appl. Phys. 72, 1748 (1992).

29. M: Yoshikawa, Y. Mori, M. Margawa, G. Katagiri, H. Ishida, and A. Ishitani, Appl. Phys. Lett. 62, 3114 (1993). 
30. J. Wagner, C. Wild, and P. Koidl, Appl. Phys. Lett. 59, 779 (1991).

31. 16. A. Erdemir, M. Switala, R. Wei, and P. Wilbur, Surface Coatings and Technology, 50 (1991)17.

32. S. V. Pepper, J. Vac. Sci. Technol., 20 (1982 643.

33. S. V. Pepper, J. Vac. Sci. Technol., 20 (1982)213.

34. F. P. Bowden and J. E. Young, Proc. Roy. Soc. London, 208 (1951)444.

35. F. P. Bowden and A. E. Hanwell, Proc. Roy. Soc., A295 (1966) 233.

36. M. N. Gardos and B. L. Soriano, J. Mater. Res., 5 (1990)2599.

37. H. Zaidi, A. Mezin, A. Nivoit, and J. Lepage, Appl. Surf. Sci., 40 (1989)103.

38. M. N. Gardos and K. V. Ravi, Diamond Films and Technology, 4(1994)139.

39. M. N. Gardos and K. V. Ravi, Carbon-Graphite-like Friction Behavior of Polycrystalline Diamond Sliding Against Itself in Vacuum, $4^{\text {th }}$ International Symposium on Diamond Materials, Reno, Nevada, 1995. 


\section{FIGURE CAPTIONS:}

Figure 1. Cross-sectional SEM micrograph of smooth diamond film used in this study (film thickness $=6 \mu \mathrm{m})$.

Figure 2. XRD spectrum of smooth diamond film.

Figure 3. Variation of friction coefficients of $\mathrm{SiC}$ pins during sliding against smooth (rms $A F M$ roughness $=30 \mathrm{~nm})$ and rough $(\mathrm{rms}$ AFM roughness $=125 \mathrm{~nm})$ diamond films in dry $\mathrm{N}_{2}$.

Figure 4. Surface SEM photomicrographs of (a) smooth (rms roughness $=30 \mathrm{~nm}$ ) and (b) rough $(\mathrm{rms}$ roughness $=125 \mathrm{~nm}$ ) diamond films used in the generation of Fig. 3 .

Figure 5. SEM photomicrographs of wear tracks formed on (a) smooth and (b) rough diamond films sliding against $\mathrm{SiC}$ pins in dry $\mathrm{N}_{2}$.

Figure 6. Variation of friction coefficients of $\mathrm{Si}_{3} \mathrm{~N}_{4}$ balls during sliding against HOPG and smooth diamond film in dry $\mathrm{N}_{2}$.

Figure 7. Friction performance of a smooth diamond film subjected to long-duration sliding test in air (Test conditions: Load, $5 \mathrm{~N}$; velocity, $0.04 \mathrm{~m} / \mathrm{s}$; relative humidity, $35 \%$ and room 
temperature).

Figure 8. 3-D surface map of wear track formed on smooth diamond film after 2.25 million sliding cycles (the depth of wear track is $0.5 \mu \mathrm{m}$ and the total thickness of the diamond film is $6 \mu \mathrm{m})$.

Figure 9. Variation of friction coefficients of $\mathrm{Si}_{3} \mathrm{~N}_{4}$ balls during sliding against HOPG and smooth diamond film in dry $\mathrm{N}_{2}$ and air.

Figure 10. Raman spectra of debris particles formed in dry $\mathrm{N}_{2}$ and air, and of smooth diamond film and graphite. 


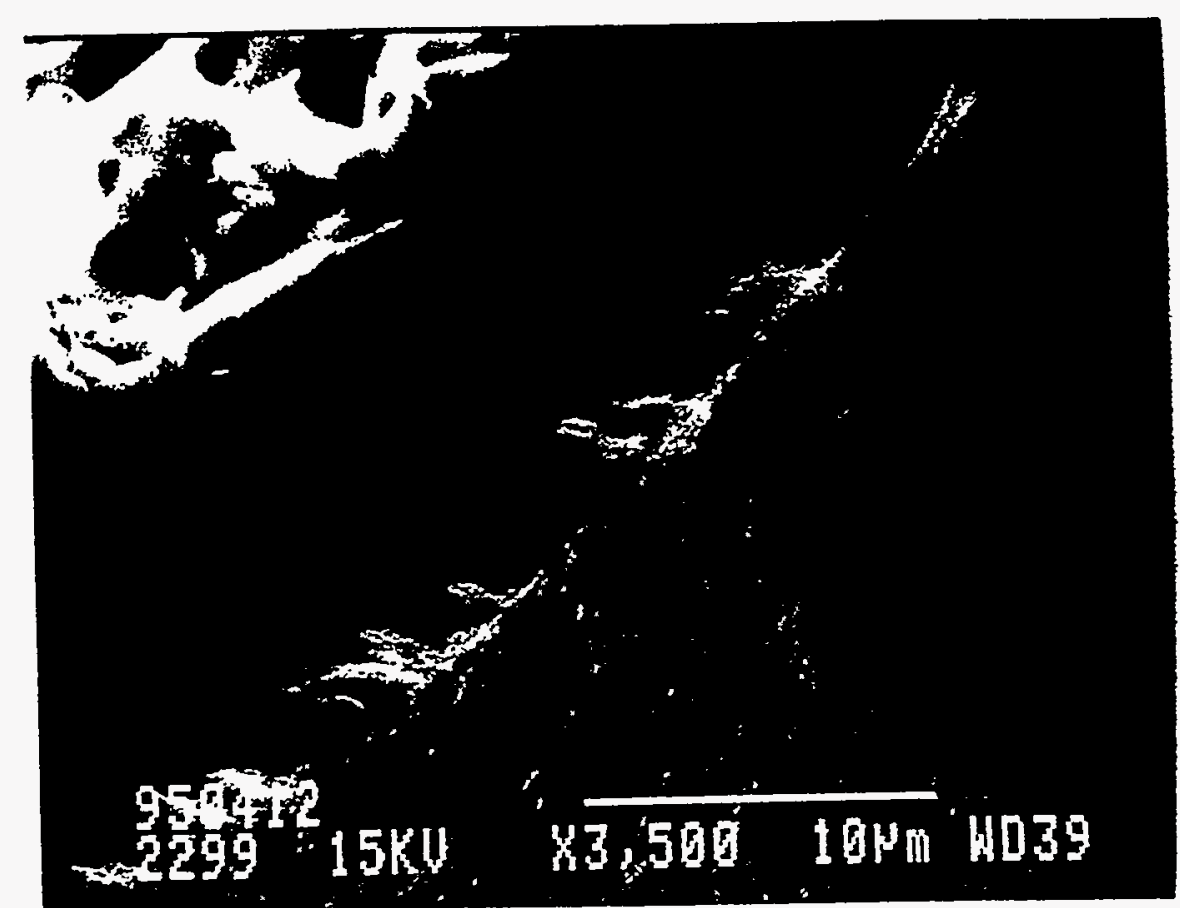

Fig. 1 


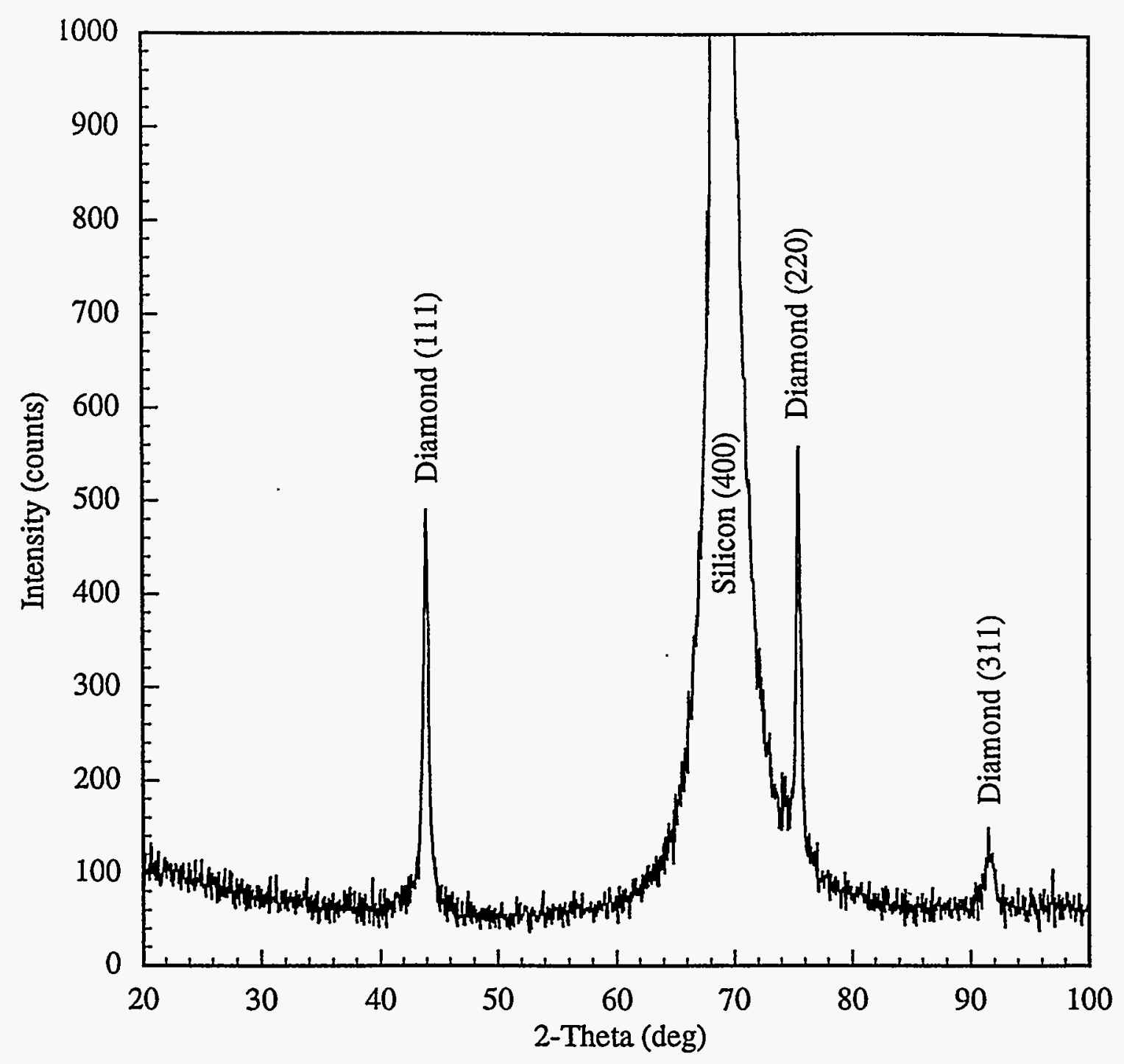

Fig. 2 


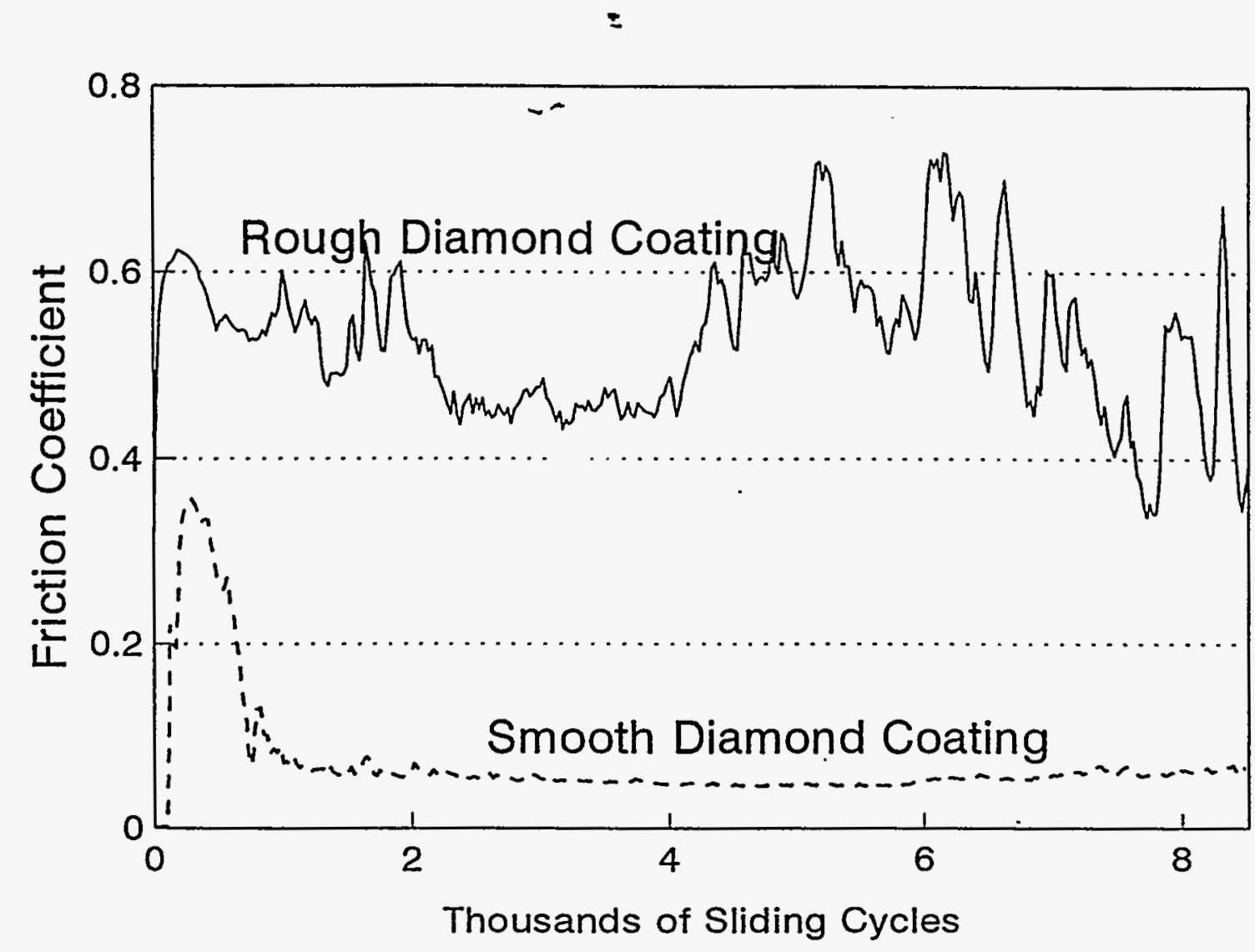

Fis. 3 


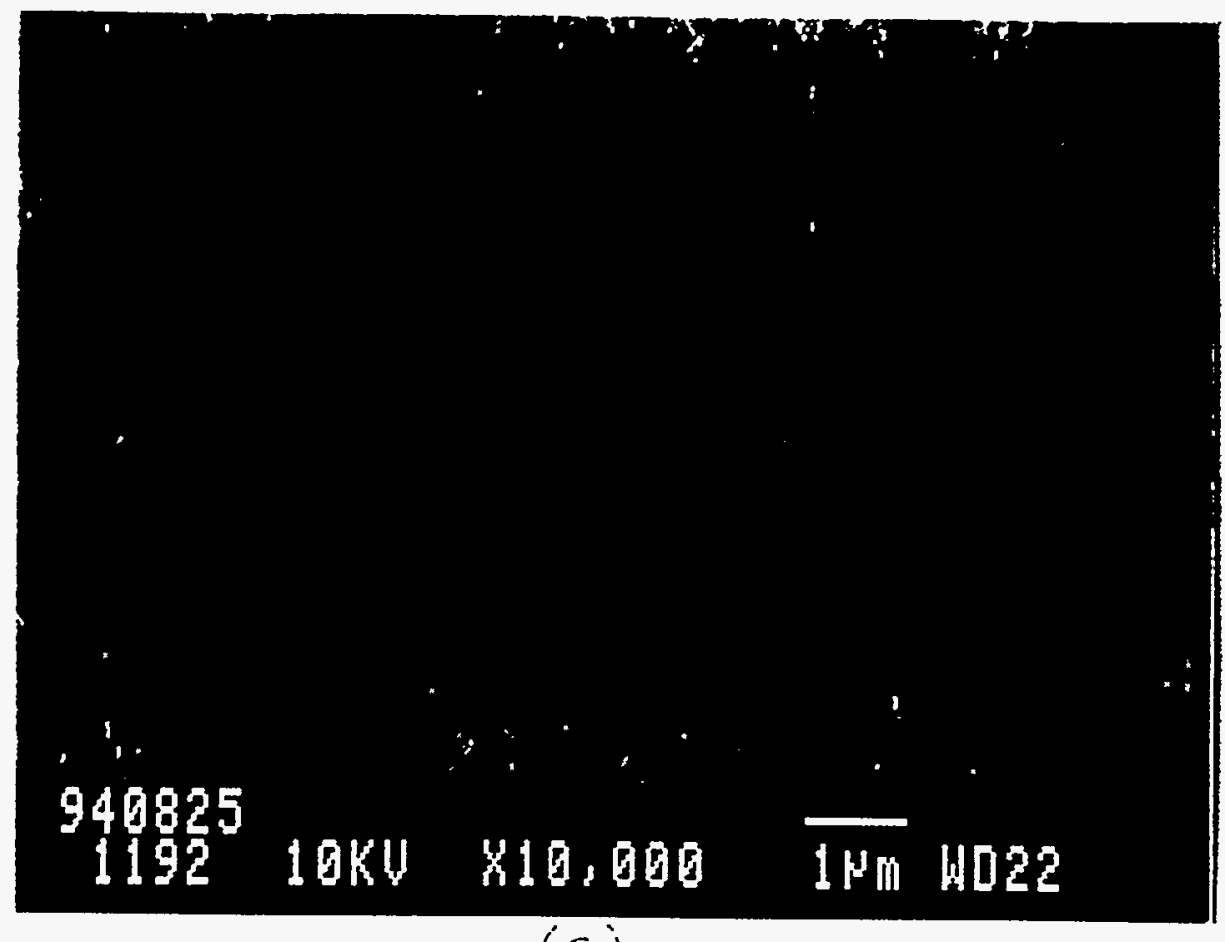

(i)

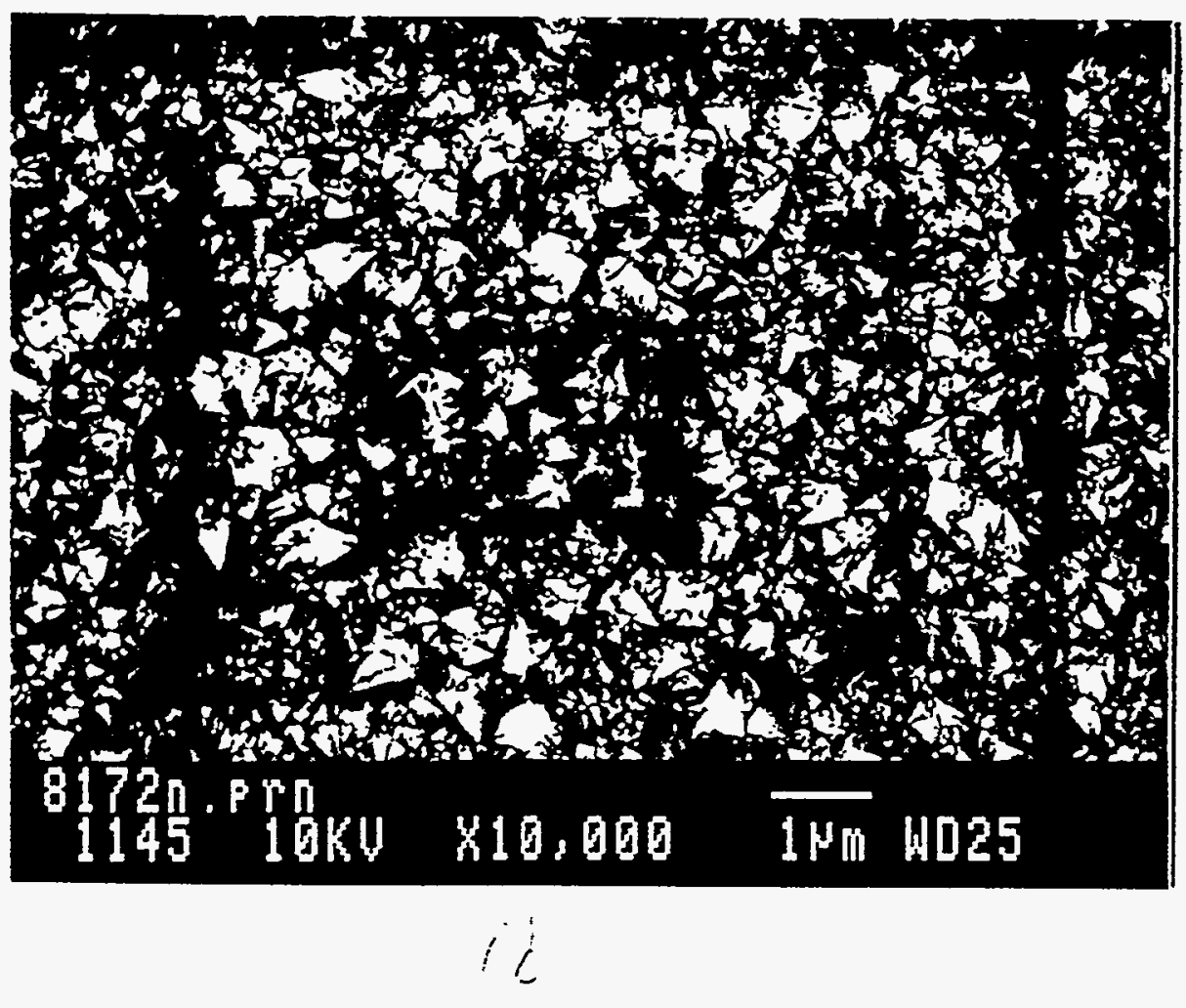



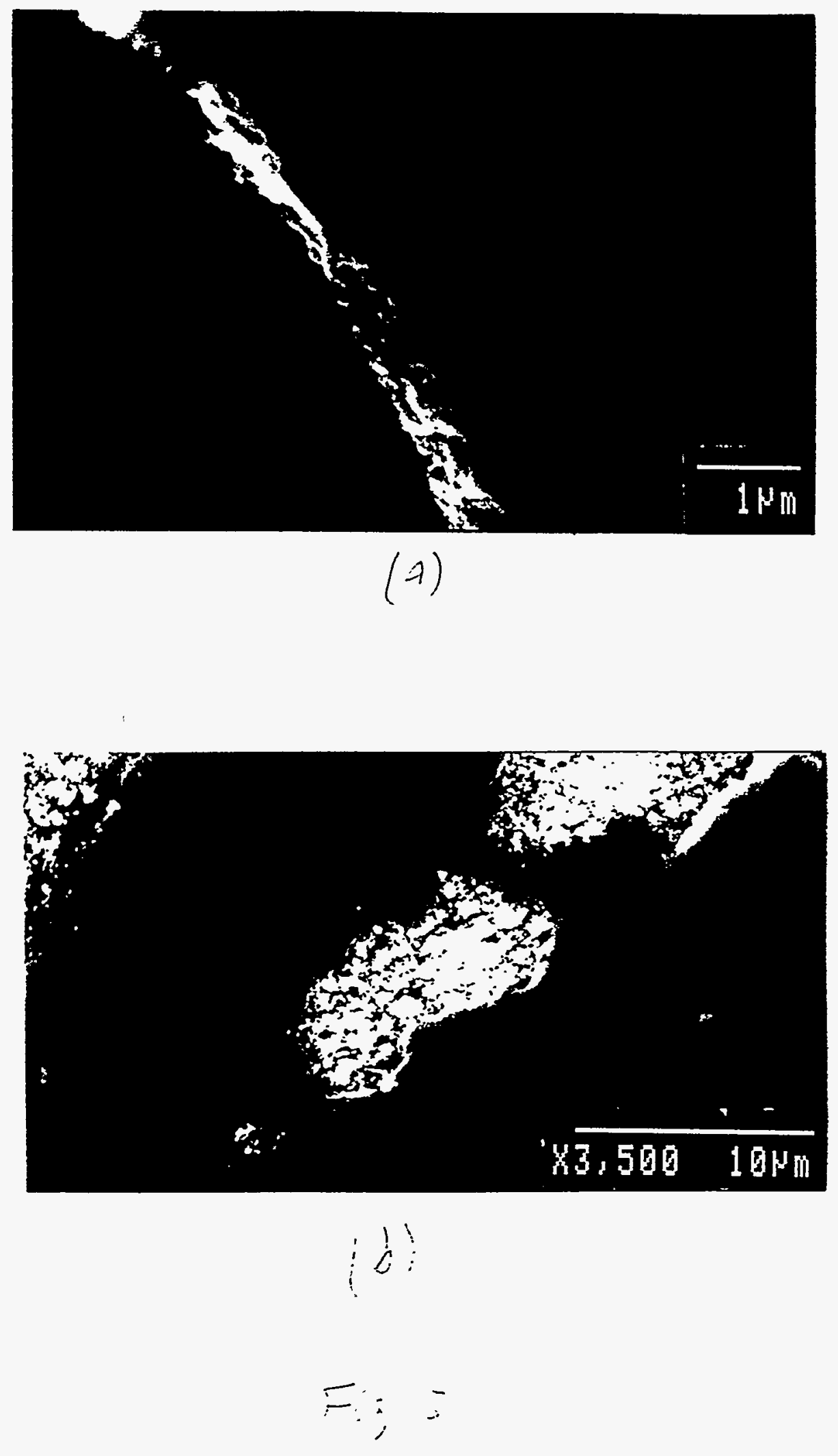


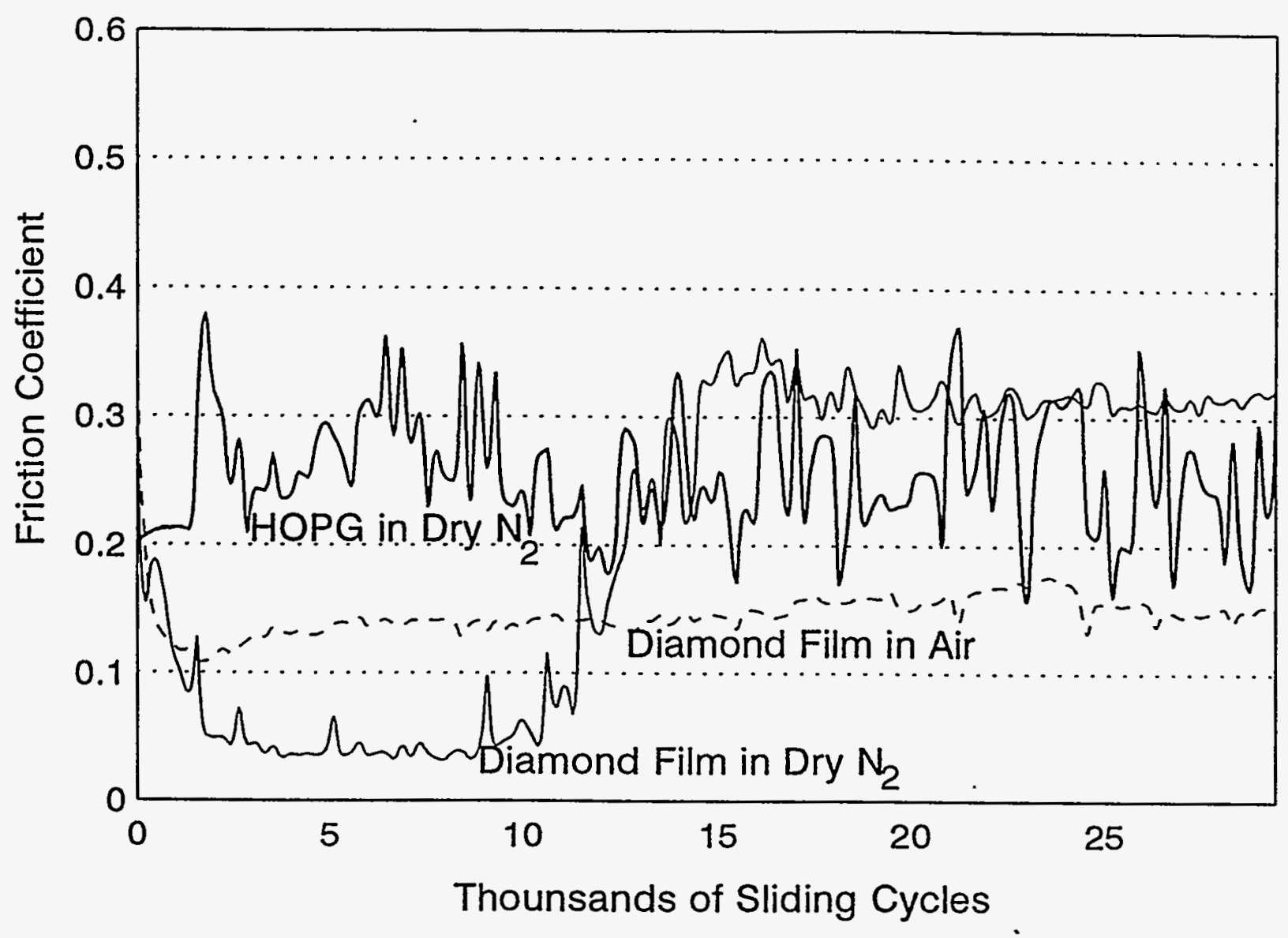

Fig. 6 


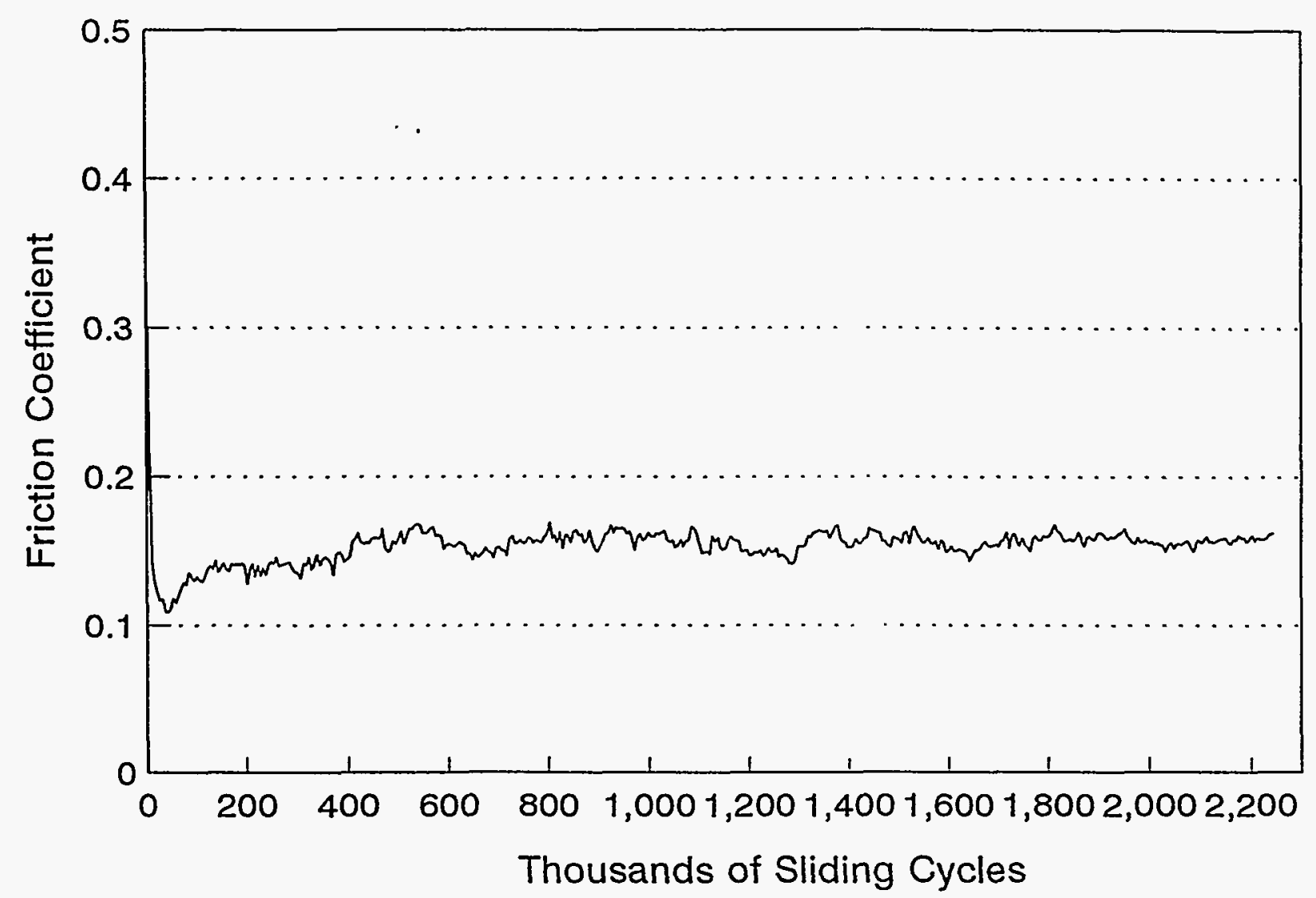

Fig.7 


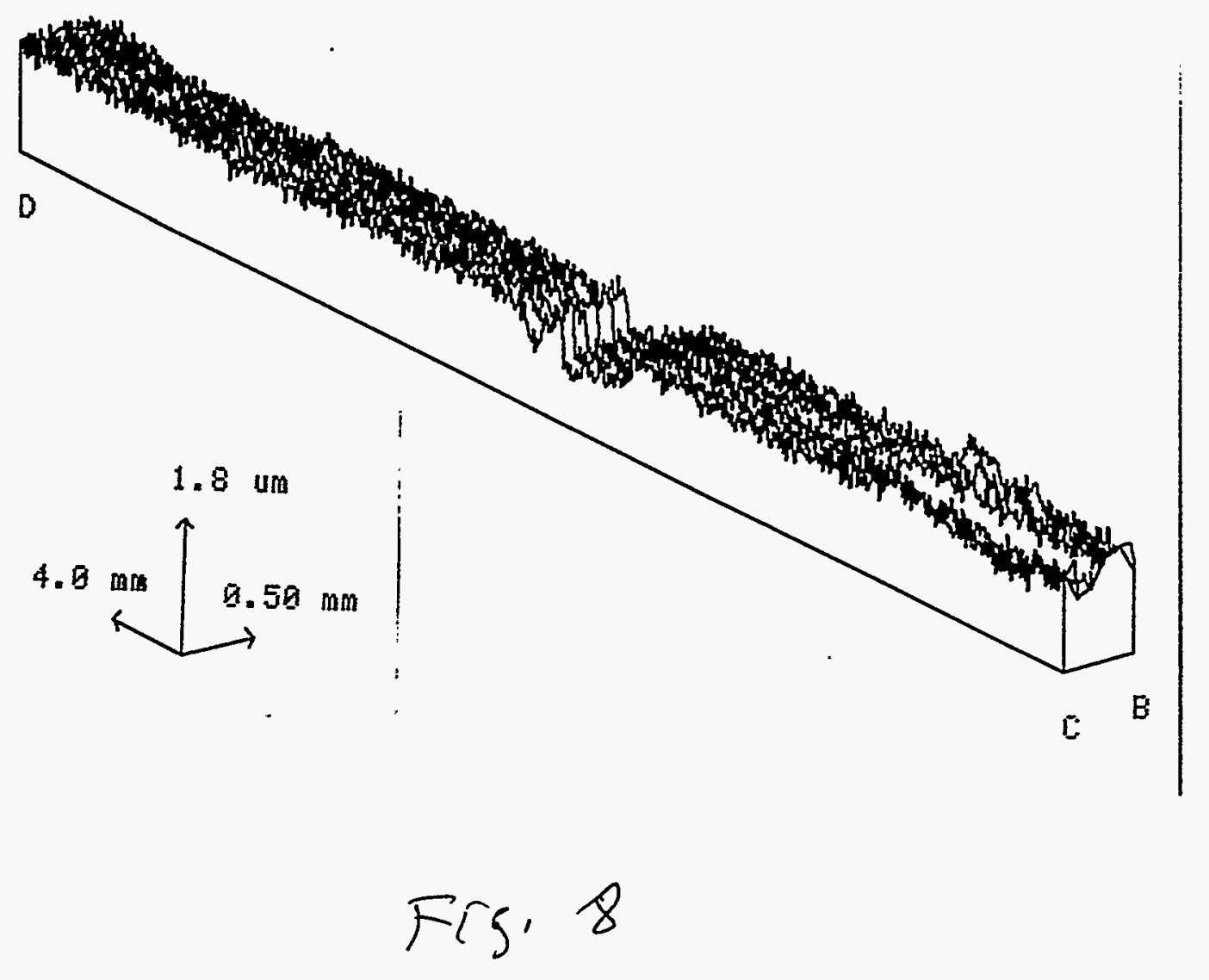




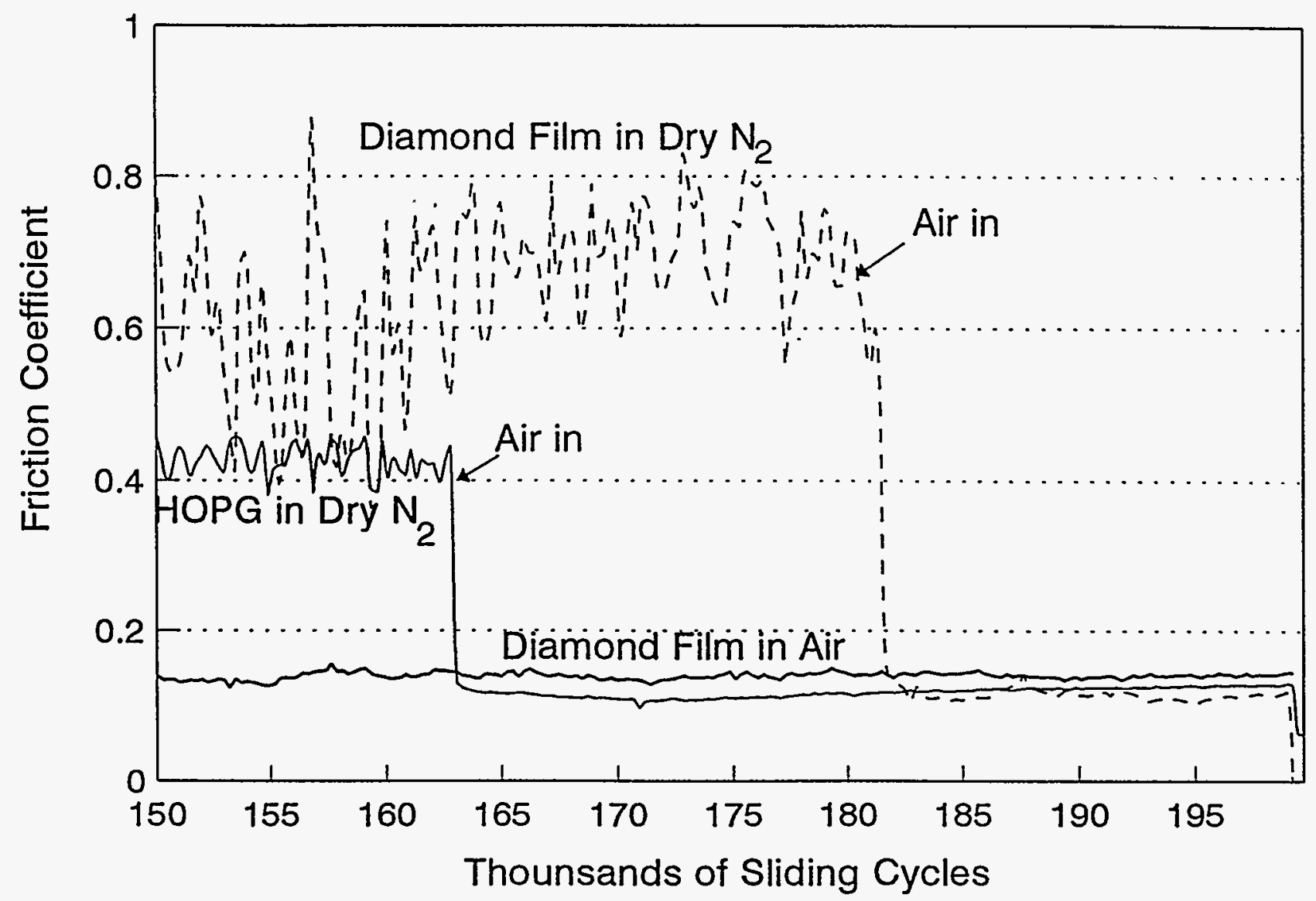

Fig. $g$ 


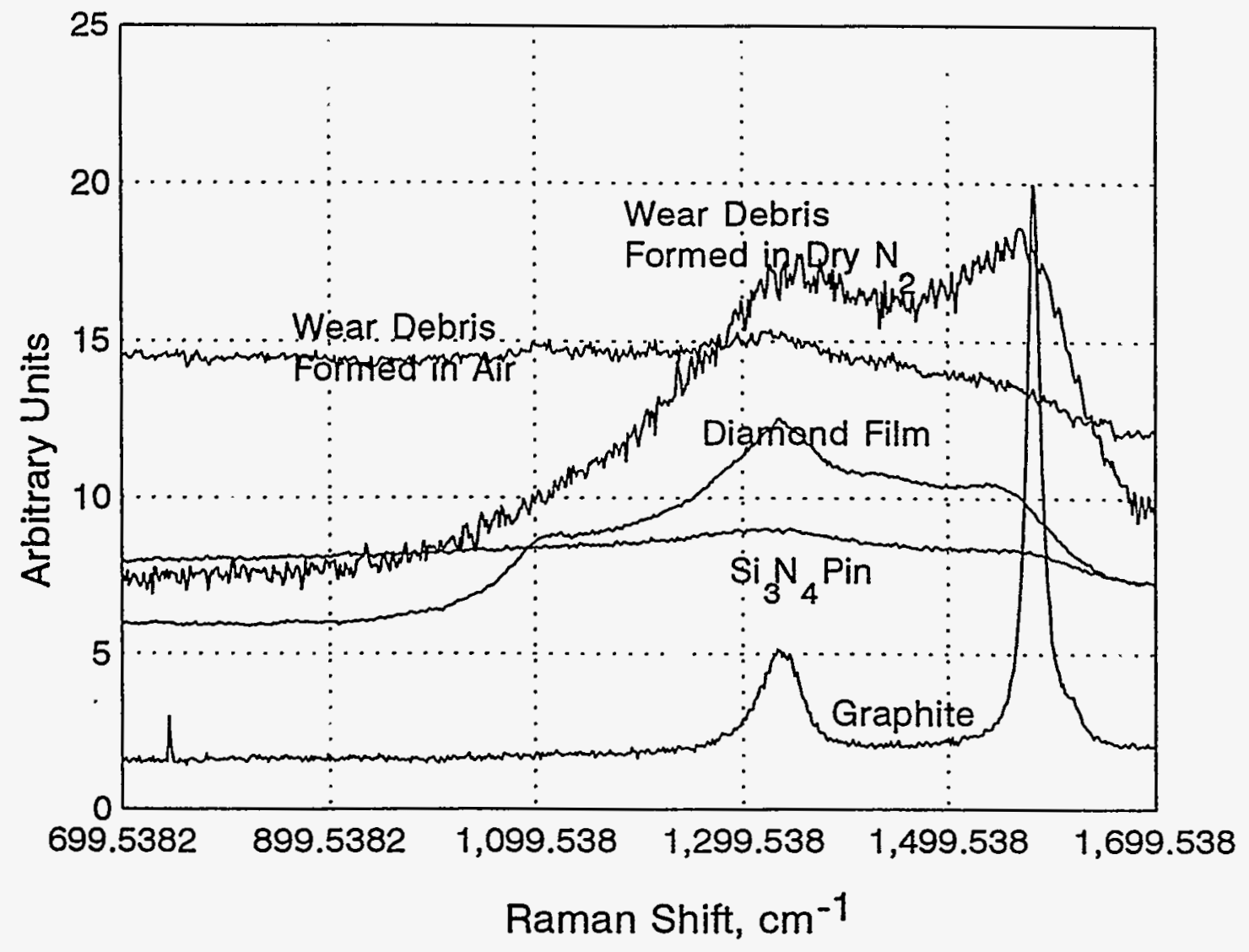

Kig.10

DISCLAIMER

This report was prepared as an account of work sponsored by an agency of the United States Government. Neither the United States Government nor any agency thereof, nor any of their employees, makes any warranty, express or implied, or assumes any legal liability or responsibility for the accuracy, completeness, or usefulness of any information, apparatus, product, or process disclosed, or represents that its use would not infringe privately owned rights. Reference herein to any specific commercial product, process, or service by trade name, trademark, manufacturer, or otherwise does not necessarily constitute or imply its endorsement, recommendation, or favoring by the United States Government or any agency thereof. The views and opinions of authors expressed herein do not necessarily state or reflect those of the United States Government or any agency thereof. 